\title{
A cross-sectional study of problem gambling and its correlates among college students in South India
}

Sanju George, Jaisoorya TS, Sivasankaran Nair, Anjana Rani, Priya Menon, Revamma Madhavan, Jeevan Chakkandan Rajan, Komath Sankaran Radhakrishnan, Vineeta Jose, Vivek Benegal, K. Thennarasu and Nancy M. Petry

\section{Background}

In the Western world, a significant portion of college students have gambled. College gamblers have one of the highest rates of problem gambling. To date, there have been no studies on gambling participation or the rates of problem gambling in India.

\section{Aims}

This study evaluated the prevalence of gambling participation and problem gambling in college students in India. It also evaluated demographic and psychosocial correlates of gambling in that population.

\section{Method}

We surveyed 5784 college students from 58 colleges in the district of Ernakulam, Kerala, India, using cluster random sampling. Students completed questionnaires that addressed gambling, substance use, psychological distress, suicidality and attention-deficit hyperactivity disorder (ADHD).

\section{Results}

A total of 5580 completed questionnaires were returned, and while only 1090 (19.5\%) college students reported having ever gambled, 415 (7.4\%) reported problem gambling. Lotteries were the most popular form of gambling. Problem gamblers in comparison with non-gamblers were significantly more likely to be male, have a part-time job, greater academic failures, higher substance use, higher psychological distress scores, higher suicidality and higher ADHD symptom scores. In comparison with non-problem gamblers, problem gamblers were significantly more likely to have greater academic failures, higher psychological distress scores, higher suicidality and higher ADHD symptom scores.

\section{Conclusions}

This study, the first to look at the prevalence of gambling in India, found relatively low rates of gambling participation in college students but high rates of problem gambling among those who did gamble. Correlates of gambling were generally similar to those noted in other countries. Since $38 \%$ of college students who had gambled had a gambling problem, there is a need for immediate public health measures to raise awareness about gambling, and to prevent and treat problem gambling in this population.

\section{Declaration of interest}

S.G. was (until October 2014) a member of the UK Responsible Gambling Strategy Board, and authored the Royal College of Psychiatrists' Faculty report FR/AP/01 Gambling: The Hidden Addiction - Future Trends in Addictions (2014).

\section{Copyright and usage}

(c) The Royal College of Psychiatrists 2016. This is an open access article distributed under the terms of the Creative commons Non-Commercial, No Derivatives (CC BY-NC-ND) licence.
Gambling is a popular leisure activity in almost all cultures. For most persons who gamble, it remains a pastime, but gambling can become problematic and have adverse consequences for an individual, family and society. Gambling disorder refers to a condition related to excessive gambling and defined by criteria set forth in the Diagnostic and Statistical Manual of Mental Disorder. ${ }^{1}$ The term problem gambling refers to a broader classification of individuals who have developed some problems with gambling but may not fulfil the diagnostic criteria for gambling disorder.

Rates of problem gambling appear to be similar in studies conducted throughout the world. In a meta-analysis of published prevalence surveys, the weighted means of combined problem gambling and gambling disorder are about $3 \%{ }^{2}$ Most of the studies to date, however, have been conducted in Western countries. There have only been two studies on the prevalence of problem gambling in Asia and none from India. The two Asian studies from Hong Kong ${ }^{3}$ and Singapore ${ }^{4}$ reported rates of problem gambling to be $4 \%$ and $2 \%$, respectively, and rates of pathological gambling to be $1.8 \%$ and $2.1 \%$, respectively.

University students seem to be particularly prone to developing gambling problems. In a meta-analysis of the prevalence surveys of gambling problems among university students from across the world, the mean rate of probable pathological gambling was reported to be $10.2 \%{ }^{5}$ Gambling participation rates among young people in Asian studies ranged from 32 to $60 \%$, problem gambling rates ranged from 1.5 to $5 \%$ and pathological gambling rates were between 0.07 and $2.66 \% .{ }^{6-9}$ Furthermore, it has been reported that $89 \%$ of probable pathological gamblers in Singapore ${ }^{7}$ and $82.8 \%$ in Hong Kong ${ }^{8}$ started gambling at or before the age of 25 years. Gambling on social occasions and lottery were the most popular forms of gambling among young people in Asian countries. ${ }^{6-9}$

Several studies have noted certain specific demographic associations with gambling problems including young age, male gender and lower socioeconomic status. ${ }^{2,5,10}$ Psychiatric disorders such as substance use disorders, depressive disorders and attention-deficit hyperactivity disorder (ADHD) are common among pathological gamblers. Both the St Louis Epidemiologic Catchment Area $(\mathrm{ECA})^{11}$ and National Epidemiologic Survey on Alcohol and Related Conditions (NESARC) ${ }^{12}$ studies have reported high cooccurrence of substance use disorders with pathological gambling. Pathological gamblers are more likely to have a lifetime diagnosis of nicotine dependence and alcohol misuse/dependence. The association of pathological gambling and substance use disorder has also been reported in young people. ${ }^{13}$ It has been noted that depressive disorder $(28-76 \%)$ is significantly higher among patients who have pathological gambling compared with the overall population. Depressive symptoms appear to be more common among individuals 
who engage in gambling. ${ }^{14,15}$ Similarly, negative affective states among university students seem to predict problem gambling. ${ }^{10}$

Pathological gambling is also closely associated with suicidal behaviours. Pathological gambling has also been reported as the third most common psychiatric disorder among people who die by suicide in countries like Hong Kong and United States, where high baseline rates of gambling have been reported. ${ }^{14,15}$ Some studies have also shown a possible association between problem gambling and ADHD with approximately $20 \%$ of pathological gamblers being diagnosed to have ADHD and another $18 \%$ having some symptoms while not qualifying for a full diagnosis. ${ }^{16}$

Though there are no studies on gambling in modern times from India, gambling has a deep origin in ancient Indian texts and scriptures, ${ }^{17}$ and it has been a popular pastime in ancient, medieval, colonial and modern India. ${ }^{18}$ The earliest account of gambling in the world is in a hymn from the Rigveda, an ancient Indian text written between 1700 and 1100 BC. Gambling is described in the Mahabharata, an epic written in $1500 \mathrm{BC}$, and various other Sanskrit and Tamil texts written in the BC era. Even during the British colonial period (17th century onwards), passion for gambling among the Indian public persisted. Particularly popular was a form of gambling called Satta or numbers gambling; examples included betting on opium, gold and cotton prices, or on the amount of rainfall.

Lawmakers grew alarmed at the gambling practices in India, and the Imperial Legislative Council enacted The Pubic Gambling Act of India in $1867^{19}$ which restricted most forms of gambling. This, in essence, made betting illegal on games of pure chance, such as Satta, and legalised on skilful games (and not just mere chance), such as horse racing. Currently, the legal forms of gambling in India are state-run lotteries, horse racing, rummy card games and casinos (in two states). Many Indians also gamble at festivals and/or fairs, as they offer a range of legal and illegal gambling opportunities, collectively referred to as 'festival gambling'. Anecdotally, illegal betting, primarily on sports such as cricket, is also popular.

Given that there are no population or university-based prevalence studies of gambling participation or problems in India and the high rates of gambling among college students in other countries, this study focused on examining college students' engagement in gambling behaviours and the prevalence of problem gambling, as well as the correlates of gambling among students in India. The data for this study were collected as part of a larger initiative to study psychological issues among college students. In this study, other than gambling behaviours, the following potential correlates were also looked at: sociodemographic variables (gender, socioeconomic status, residence, part-time job); academic variable (failed in a subject in exams); and psychological variables (lifetime use of alcohol, tobacco and cannabis, psychological distress, suicidal thoughts and attempts, and symptoms of ADHD).

\section{Method}

\section{Sampling}

This survey was conducted in 58 colleges in the district of Ernakulam, Kerala, India. These institutions were selected using cluster random sampling. The master list was first categorised into institutions offering various courses: medical, dental, nursing, engineering, law, arts and sciences, homeopathy, ayurveda and fisheries. At least $40 \%$ of institutions in each subcategory were randomly selected, and for colleges that were few in number (e.g. medical, dental, law, homeopathy, ayurveda and fisheries colleges), at least $50 \%$ were selected to ensure representation in these disciplines. Classes in Indian colleges only have students from the same year and doing the same course as opposed to colleges in Western countries that typically have students from various years/courses in the same class. Prior permission was sought and received from each of the colleges for participation in the study. The survey was carried out over a period of 3 months.

A power analysis was conducted to identify the minimum sample size necessary to be able to calculate a $1 \%$ prevalence rate with $95 \%$ CI. Based on this power analysis, at least 3520 students were needed to participate to assess this prevalence rate. From each institution, the college administrative team randomly selected students studying in odd years or even years (i.e. first year and third year, or second year and fourth year).

Researchers administered paper and pencil questionnaires and informed students that all information was anonymised; there are no right or wrong answers, and answers would not impact their course grades in any way. Verbal consent was obtained from students. All consenting students were given the questionnaires. Participants read through the questionnaire and if they had queries, a healthcare professional was at hand to clarify matters. It was administered in a classroom setting with students sitting sufficiently apart so that answers could not be revealed to or discussed with each other. Participants took about $50 \mathrm{~min}$ on average to complete the questionnaire. No incentives were given for completing the questionnaires.

On the day of the survey, 5784 students were present, and approximately $2.5 \%$ of the students were absent and did not complete the survey. Of the questionnaires returned, 5580 questionnaires are included in these analyses. The remaining 204 (3.5\%) questionnaires were excluded as they were returned incomplete.

\section{Ethical considerations}

Institutional ethical approval was received from the host organisation, and administrative approvals were received from the college authorities prior to the survey. Only students who verbally consented to participate took part in the study. Those who did not want to participate were free to leave the classroom (but none did) or not complete the questionnaire (and only 3.5\% of questionnaires were returned incomplete).

\section{Instruments}

Standardised instruments were administered to address gambling, substance use, psychological distress, and ADHD. All questionnaires were designed in English and translated into Malayalam (the vernacular language). Another set of translators translated back to English.

\section{Gambling}

Questions were asked about participation in various types of gambling activities (lottery, cricket/football gambling, cards, festival gambling, online gambling (other than lottery), online lottery, Satta, horse racing, others (not specified)). NODS-CLiP, a three-item screening tool based on DSM-IV gambling diagnosis, was also administered. One item asked, 'Have you ever tried to stop, cut down, or control your gambling?' The other two were: 'Have you ever lied to family members, friends or others about how much you gamble or how much money you lost on gambling?' and 'Have there been periods lasting 2 weeks or longer when you spent a lot of time thinking about your gambling experiences, or planning out future gambling ventures or bets?'. High rates of specificity and sensitivity in classifying problem gambling have been reported among those who endorse one or more of the three NODS-CLiP items. ${ }^{20}$

\section{Substance use}

The Alcohol, Smoking and Substance Involvement Screening Test (ASSIST) assessed the lifetime use of various psychoactive 


\begin{tabular}{|c|c|c|c|c|}
\hline Activity & $\begin{array}{c}\text { Non-problem } \\
\text { gamblers, } \\
n(\%)\end{array}$ & $\begin{array}{c}\text { Problem } \\
\text { gamblers, } \\
n(\%)\end{array}$ & $\begin{array}{c}\chi^{2} \\
\text { value }\end{array}$ & $P$ \\
\hline Lottery & $394(58.4)$ & $176(42.4)$ & 26.2 & $<0.001$ \\
\hline $\begin{array}{l}\text { Cricket/football } \\
\text { gambling }\end{array}$ & 179 (26.5) & $124(29.9)$ & 1.4 & 0.23 \\
\hline Cards & $73(10.8)$ & 105 (25.3) & 39.4 & $<0.001$ \\
\hline Festival gambling & $70(10.4)$ & $45(10.8)$ & 0.1 & 0.80 \\
\hline $\begin{array}{l}\text { Online gambling } \\
\text { (other than lottery) }\end{array}$ & $22(3.3)$ & $32(7.7)$ & 10.8 & 0.001 \\
\hline Online lottery & $18(2.7)$ & $15(3.6)$ & 0.8 & 0.37 \\
\hline Satta & $17(2.5)$ & $13(3.1)$ & 0.4 & 0.54 \\
\hline Horses & $10(1.5)$ & $14(3.4)$ & 4.2 & 0.04 \\
\hline Other, not specified & $112(16.6)$ & $62(14.9)$ & 0.5 & 0.469 \\
\hline
\end{tabular}

substances. ${ }^{21}$ For the present study, we evaluated the lifetime use of alcohol, nicotine, and cannabis, but not other substances. The ASSIST has good test-retest reliability and high discriminative validity. ${ }^{22}$

\section{Psychological distress}

Kessler's Psychological Distress Scale (K10) assessed frequency of depressive and anxiety symptoms over the past month on a 4-point Likert scale. ${ }^{23}$ This tool has been validated to screen for common mental disorders in developing country settings including India. ${ }^{24,25}$

\section{Suicidality}

Two questions assessed lifetime suicidality: 'Have you ever thought of committing suicide in your life?' and 'Have you made a suicidal attempt in your lifetime?'.

ADHD

Barkley Adult ADHD rating scale-IV (BAARS-IV) childhood symptoms was used to retrospectively self-report ADHD symptoms which occurred between 5 and 12 years of age. ${ }^{26}$ It consists of 18 questions: 9 related to inattention and 9 for hyperactivity-impulsivity with each question being rated on a 4-point Likert scale.

\section{Statistical analyses}

Lifetime prevalence of gambling participation and problem gambling were determined, using endorsement of one or more NODS$\mathrm{CLiP}$ items as constituting problem gambling. Between the three groups (non-gamblers, non-problem gamblers and problem gamblers), two group comparisons were done: between non-gamblers and problem gamblers and non-problem and problem gamblers. Sociodemographic variables, academic performance, substance use, psychological distress and suicidality were compared between the groups using chi-square tests. Differences in mean symptom scale scores were compared between groups using independent $t$-test. All tests were two-tailed and statistical significance was set at $P<0.05$. SPSS version 15 was used for all analyses. ${ }^{27}$

\section{Results}

In all, 5580 completed questionnaires were obtained from 58 different colleges. The mean age of the sample was 19.5 (s.d.=1.9) years (range $=17-25$ years). Of these 5580 questionnaires, 1917 respondents were men (34.4\%) and 3663 (65.6\%) women, similar to the proportions found in the colleges surveyed, other than engineering colleges which had predominately male students. In terms of economic status, this sample was reflective of the general population for the region.

Of the total sample, 1090 (19.5\%) individuals had gambled at least once. Of these 1090 individuals, 675 (12.1\%) were classified as non-problem gamblers using scores of 0 on the NODS-CLiP and $415(7.4 \%)$ as problem gamblers with scores of one or higher. In the total sample, $319(5.7 \%)$ scored 1 on the NODS-CLiP, $70(1.3 \%)$ scored two and $26(0.5 \%)$ scored three. Of the 1090 individuals who had ever gambled, 415 (38.1\%) were problem gamblers.

Table 1 shows participation in various forms of gambling activities among non-problem gamblers and problem gamblers. The lottery was the most popular form of gambling, followed by betting on football and cricket, and playing card games. A small minority reported gambling online; 787 (14.1\%) had participated in only one type of gambling activity, $195(4.3 \%)$ had participated in two forms of gambling, $66(1.0 \%)$ had participated in three forms of gambling and $42(0.6 \%)$ students had taken part in more than three types.

Tables 2 and 3 detail the sociodemographic, academic and psychological variables across non-gamblers, non-problem gamblers and problem gamblers. Problem gamblers when compared with non-gamblers were significantly more likely to be male and have a part-time job, whereas non-problem gamblers and problem gamblers were comparable with regard to sociodemographic profile (Table 2). Problem gamblers when compared with non-gamblers were significantly more likely to have poor academic performance, higher lifetime use of alcohol, tobacco and cannabis, greater psychological distress, more suicidal thoughts and attempts, and higher ADHD symptom scores (Table 3). Problem gamblers when compared with non-problem gamblers were significantly more likely to have poor academic performance, psychological distress, suicidal thoughts, suicidal attempts and higher ADHD symptom scores (Table 3).

\begin{tabular}{|c|c|c|c|c|c|}
\hline Sociodemographic variables & $\begin{array}{l}\text { Non-gamblers, } \\
n(\%)\end{array}$ & $\begin{array}{l}\text { Non-problem gamblers, } \\
\qquad(\%)\end{array}$ & Problem gamblers, $n$ (\%) & $\begin{array}{c}\chi^{2}(P) \\
(\text { Group I V. IIII) }\end{array}$ & $\begin{array}{c}\chi^{2}(P) \\
(\text { Group II V. III) }\end{array}$ \\
\hline Male & $1239(28.1)$ & $405(62.0)$ & $273(66.6)$ & $195.4(<0.001)$ & $2.1(0.15)$ \\
\hline \multicolumn{6}{|l|}{ Socioeconomic status } \\
\hline Above poverty line & $3673(82.6)$ & $560(83.2)$ & $349(85.1)$ & $1.14(0.284)$ & $0.40(0.53)$ \\
\hline Below poverty line & $776(17.4)$ & $113(16.8)$ & $61(14.9)$ & & \\
\hline \multicolumn{6}{|l|}{ Residence } \\
\hline City & $1021(23.6)$ & $182(28.3)$ & $92(22.7)$ & $0.317(0.284)$ & $2.2(0.119)$ \\
\hline Town & $796(18.4)$ & $120(18.7)$ & $74(18.3)$ & & \\
\hline Village & $2513(58.0)$ & 341 (53.0) & $239(59.0)$ & & \\
\hline Part-time job & $284(6.3)$ & 96 (14.2) & $63(15.2)$ & $30.04(<0.001)$ & $0.103(0.748)$ \\
\hline
\end{tabular}




\begin{tabular}{|c|c|c|c|c|c|}
\hline & $\begin{array}{l}\text { Non-gamblers } \\
\quad(n=4490)\end{array}$ & $\begin{array}{c}\text { Non-problem } \\
\text { gamblers }(n=675)\end{array}$ & $\begin{array}{l}\text { Problem gamblers } \\
\qquad(n=415)\end{array}$ & $\begin{array}{c}\chi^{2}(P) \\
(\text { Group I V. III) }\end{array}$ & $\begin{array}{c}\chi^{2}(P) \\
\left(_{\text {Group } \| \text { V. III) }}^{a}\right.\end{array}$ \\
\hline Failed in a subject in exams & $763(17.0)$ & $123(18.2)$ & $97(23.4)$ & $10.36(0.001)$ & $4.40(0.04)$ \\
\hline Lifetime alcohol use & $760(17.0)$ & $255(38.3)$ & $164(39.9)$ & $95.04(<0.001)$ & $0.287(0.592)$ \\
\hline Lifetime tobacco use & $292(6.5)$ & $116(17.3)$ & 78 (18.9) & $60.05(<0.001)$ & $0.46(0.504)$ \\
\hline Lifetime cannabis use & $50(1.1)$ & $22(3.3)$ & $20(4.9)$ & $27.03(<0.001)$ & $1.489(0.222)$ \\
\hline $\begin{array}{c}\text { Psychological distress } \\
\text { score, mean (s.d.) }\end{array}$ & $17.6(0.4)$ & $17.9(0.5)$ & $23.0(1.1)$ & $8.8(<0.001)^{b}$ & $5.8(<0.001)^{b}$ \\
\hline Suicidal thoughts & 908 (20.2) & $166(24.6)$ & $126(30.4)$ & $21.58(<0.001)$ & $4.3(0.04)$ \\
\hline Suicide attempt & $169(3.8)$ & $27(4.0)$ & $32(7.7)$ & $15.94(<0.001)$ & $7.12(0.008)$ \\
\hline $\begin{array}{l}\text { ADHD symptom score, } \\
\text { mean (s.d.) }\end{array}$ & $26.3(0.5)$ & $28.6(0.6)$ & $29.2(1.5)$ & $10.3(<0.001)^{b}$ & $3.6(0.001)^{b}$ \\
\hline
\end{tabular}

\section{Discussion}

To the best of our knowledge, this is the first study of gambling participation and problems from India. Only $19.5 \%$ of this sample reported having ever gambled which is lower than that found in previous studies from Asia in young people where gambling participation rate has varied between 32 and $60 \%{ }^{6-9}$ The overall low rate of gambling participation noted in this study relative to that in other college student samples ${ }^{5}$ could be related to limited availability of gambling or a lack of acceptance of gambling as a leisure activity in the Indian culture. Alternatively, the questionnaires administered may not reliably and validly assess gambling in Indian students, and perhaps Indian students are less willing to admit to gambling than those in other countries.

Importantly, in our study, of the people who ever gambled, more than one-third (38.1\%) were classified as problem gamblers, according to NODS-CLiP responses. Thus, although the rate of gambling was low in comparison to studies from other countries, the overall prevalence of problem gambling was $7.4 \%$, within the range of that reported in other college student samples. The country-specific rates of probable pathological gambling reported in a meta-analysis of studies ${ }^{5}$ of university students are as follows: United States (ranged from 3 to $32 \%$ ), Canada (8.7\%), Scotland (3.9\%), Japan (4.2\%), Nigeria (14.2\%) and China (6.4\%). In the four Asian countries where it is legal to gamble (Macau, Hong Kong, Singapore and South Korea), problem gambling rates ranged from 1.5 to $5 \%$ and pathological gambling rates were between 0.07 and $2.66 \%$ in young people. ${ }^{28}$ These data suggest that in India, there are significantly high rates of problem gambling among those who gamble. This could mean that a higher proportion of students who gamble are likely to develop problems from it, or that the questionnaire overestimated gambling problems in this sample.

However, the correlates of gambling and problem gambling identified in this study are consistent with those noted in other studies conducted around the world. In this study as in those from Western countries, college students who were problem gamblers were more likely to be men, have access to disposable income by having a part-time job and have poor academic performance. ${ }^{29-31}$ Problem gamblers in our sample were more likely to have had a lifetime history of the use of alcohol, tobacco and cannabis which adds further support to the robust finding that there is a strong association between problem gambling and substance use. ${ }^{11-13,29}$ High levels of psychological distress and suicidality among the students who gambled supports previous findings of links between gambling, depression and suicidality. ${ }^{14,15}$ Similar to previous studies, our students with ADHD symptoms were overrepresented in the gambling group. ${ }^{16}$ Most previous studies looking at comorbidity have included individuals who had a diagnosis of pathological gambling and hence a direct comparison between the correlates of problem gamblers in our study and previous studies may not be valid; nevertheless, this is interesting.

The strengths of this study are the following: this is the first study of gambling participation and problems in India; use of structured instruments for screening gambling issues and issues related to gambling; and it included a large number of college students from a number of different colleges and courses from an array of institutions, so findings can be generalised within the state. Limitations of this study include the following: these results may not be generalisable to the larger Indian population, as the study was limited to university students; many of the instruments have not been validated specifically in Indian populations; as a questionnaire-based study, diagnostic interviews were not included to validate reported findings; this study was cross-sectional in nature, and the data cannot strictly be used to support directionality or causality between gambling and the various correlates reported.

Given the lack of research in the field of gambling in India, it is clear that more needs to be done to address this issue. College counsellors and health departments need to become aware of gambling problems and receive training in the identification and treatment of this condition. Data from this study show that college students in India engage in gambling at problematic levels, and more than one in three of those who gamble appear to have some degree of a gambling problem. The increasing availability of and accessibility to gambling opportunities in India will likely lead to an increase in both rates of gambling participation and problem gambling. Hence, we make a call for there to be an increased awareness of gambling and problem gambling among the public, college students, educators, healthcare professionals and policymakers that should lead to measures being adopted to help those who are affected. We also call for a wider debate about the positioning of gambling addiction within mainstream psychiatry, alongside substance use disorders and aligned within public health from a policy perspective.

\section{Recommendations for future research}

In our view, studies need to be carried out to estimate the prevalence of gambling and problem gambling among the general population in India. In addition, gambling habits of high-risk groups such as young people, and those with comorbid mental disorders or other addictions, need further exploration. A better understanding, through research, of how Indians gamble and what problems ensue is much needed for implementing effective interventions including prevention. 
Sanju George, FRCPsych, Rajagiri Hospital, Chunagamvely, Aluva, Kerala, India; Jaisoorya TS, MD, MRCPsych, Psychiatry, National Institute of Mental Health and Neurosciences, Bangalore, India; Sivasankaran Nair, DPM, Department of Psychiatry, Government Medical College, Ernakulam, India; Anjana Rani, MD, Department of Psychiatry, Government Medical College, Ernakulam, India; Priya Menon, DPM, Department of Psychiatry, Government Medical College, Ernakulam, India; Revamma Madhavan, MSW, Department of Psychiatry, Government Medical College, Ernakulam, India; Jeevan Chakkandan Rajan, MSC, MPhil, Department of Psychiatry, Government Medical College, Ernakulam, India; Komath Sankaran Radhakrishnan, DPM, Department of Psychiatry, Government Medical College, Ernakulam, India; Vineeta Jose, MBBS, Department of Psychiatry, Government Medical College, Ernakulam, India; Vivek Benegal, MD, Unit of Addiction Medicine, NIMHANS, Bangalore, India; K. Thennarassu, PhD, Biostatistics, NIMHANS, Bangalore, India; Nancy M. Petry, PhD, Medicine, University of Connecticut School of Medicine, Farmington, Connecticut, USA

Correspondence: Sanju George, Rajagiri Hospital, Chunagamvely, Aluva - 683112 , Kerala, India. Email: sanjugeorge531@gmail.com

First received 27 Nov 2015, final revision 10 Mar 2016, accepted 11 Mar 2016

\section{Acknowledgements}

The authors wish to thank all the staff at all participating colleges who provided administrative and logistic support for the research project, and Mr Ajayakumar and team who helped with data entry. We also thank all students who took part in this survey.

\section{References}

1 American Psychiatric Association. Diagnostic and Statistical Manual of Menta Disorders (5th edn) (DSM-5). APA, 2013.

2 Stucki S, Rihs-Middel M. Prevalence of adult problem and pathological gambling between 2000 and 2005: an update. J Gamb/ Stud 2007; 23: 245-57.

3 Wong IL, So EM. Prevalence estimates of problem and pathological gambling in Hong Kong. Am J Psychiatry 2003; 160: 1353-4.

4 Ministry of Community Development, Ya S. More than Half of Singapore Gambles; but Only 2 in 100 at Risk of Gambling Addiction. Ministry of Community Development, 2005 (www.mcys.gov.sg).

5 Nowak DE, Aloe AM. The prevalence of pathological gambling among college students: a meta-analytic synthesis, 2005-2013. J Gambl Stud 2014; 30 $819-43$

6 Park S Cho MJ, Jeon HJ, Lee HW, Bae JN, Park Jl, et al. Prevalence, clinical correlations, comorbidities, and suicidal tendencies in pathological Korean gamblers: results from the Korean Epidemiologic Catchment Area Study. Soc Psychiatry Psychiatr Epidemiol 2010; 45: 621-9.

7 National Council on Problem Gambling. Report of Survey on Participation in Gambling Activities among Singapore Residents. 2011 (https://www.ncpg.org.sg/ en/pdf/2011_NCPG_Gambling Participation_Survey_23_Feb_2012.pdf).

8 Home Affairs Bureau. Study on Hong Kong Peoples' Participation in Gambling Activities: Key Statistics. 2005 (http://www.hab.gov.hk/file manager/en/documents/whats_new/gambling/KeyStat_200514_e.pdf).

9 University of Macau. A Study on Macau Peoples' Participation in Gambling Activities. Institute for the Study of Commercial Gaming, University of Macau, 2003 (http://www.umac.mo/iscg/Events/Seminar/S1_SummaryReport_ENG.pdf).

10 Moore SM, Thomas AC, Kale S, Spence M, Zlatevska N, Staiger PK, et al. Problem gambling among international and domestic university students in Australia: who is at risk? J Gambl Stud 2013; 29: 217-30.

11 Cunningham-Williams RM, Cottler LB, Compton WM 3rd, spitznagel EL. Taking chances: problem gamblers and mental health disorders - results from

the St Louis Epidemiologic Catchment Area Study. Am J Public Health 1998; 88 1093-6.

12 Petry NM, Stinson FS, Grant BF. Comorbidity of DSM-IV pathological gambling and other psychiatric disorders: results from the National Epidemiologic Survey on Alcohol and Related Conditions. J Clin Psychiatry 2005; 66: 564-74.

13 Lynch WJ, Maciejewski PK, Potenza MNA. Psychiatric correlates of gambling in adolescents and young adults grouped by age at gambling onset. Arch Gen Psychiatry 2004; 61: 1116-22.

14 Chen EY, Chan WS, Wong PW, Chan SS, Chan CL, Law YW, et al. Suicide in Hong Kong: a case-control psychological autopsy study. Psychol Med 2006; 36 $815-25$

15 Kim SW, Grant JE, Eckert ED, Faris PL, Hartman BK. Pathological gambling and mood disorders: clinical associations and treatment implications. J Affect Disord 2006; 92: 109-16.

16 Specker SM, Carlson GA, Christenson GA, Marcotte M. Impulse control disorders and attention-deficit disorder in pathological gamblers. Ann Clin Psychiatry 1995; 7: 175-9.

17 MacDonell AA. A Vedic Reader for Students Containing Thirty Hymns of the Rig Veda in the Original Samhita and Pada Texts, with Transliteration, Translation, Explanatory Notes, Introduction Vocabulary: 187-94. Motilal Banarsidass Publishers, 1992.

18 Benegal V. Gambling experiences, problems and policy in India: a historical analysis. Addiction 2013; 108: 2062-7.

19 The Public Gaming Act India, 1867 (http://www.sangrurpolice.in/wp-content/ themes/intrepidity/images/actrule/publicGamblingAct1867.pdf).

20 Toce-Gerstein M, Gerstein D, Volberg RA. The NODS-CLiP: a rapid screen for adult pathological and problem gambling. J Gamb/ Stud 2009; 25: 541-55.

21 WHO ASSIST Working Group. The Alcohol, Smoking and Substance Involvement Screening Test (ASSIST): development, reliability and feasibility. Addiction 2002; 97: 1183-94.

22 Humeniuk RE, Ali RA, Babor TF, Farrell M, Formigoni ML, Jittiwutikarn J, et Validation of the Alcohol Smoking and Substance Involvement Screening Test (ASSIST). Addiction 2008; 103: 1039-47.

23 Andrew G, Slade T. Interpreting scores on the Kessler Psychological Distress Scale. Aust NZ J Public Health 2001; 25: 494-7.

24 Huang JP, Xia W, Sun CS, Zhang HY, WU LJ. Psychological distress and its correlates in Chinese adolescents. Aust NZ J Psychiatry 2009; 43: 674-81.

25 Kessler RC, Üstün TB (eds). The WHO World Mental Health Survey: Global Perspectives on the Epidemiology of Mental Disorders. Cambridge University Press, 2008.

26 Barkley RA. Barkley Adult ADHD Rating Scale - IV (BAARS-IV) - Childhood Symptoms. Guilford Press, 2011.

27 Statistical Package for Social Sciences (SPSS) Inc. SPSS for Windows, Version 15.0 SPSS, 2006.

28 Liua L, Luoa T, Haoa W. On gambling problems in young people: experience from the Asian region. Curr Opin Psychiatry 2013; 26: 310-17.

29 Goldstein AL, Walton MA, Cunningham RM, Reska SM, Duan L. Correlates of gambling among youth in an inner-city emergency department. Psychol Addict Behav 2009; 23: 113-21.

30 Petry NM. Pathological Gambling: Etiology, Comorbidity, and Treatment. APA, 2005.

31 Toneatto $T$, Nguyen L. Individual characteristics and problem gambling behavior. In Research and Measurement Issues in Gambling Studies (eds Smith G, Hodgins DC, Williams RJ): 279-303. Academic Press, 2007 